\title{
To study the association of Doppler derived indices of uterine artery resistance with composite of $\mathrm{PIH} / \mathrm{PET}$
}

\author{
Uday Bhanu Rana*, Santosh Minhas, Prakash Negi, Kushla Pathania, Simar Preet Kaur
}

Department of Obstetrics and Gynecology, Indira Gandhi Medical College, Shimla, Himachal Pradesh, India

Received: 18 December 2016

Revised: 10 January 2017

Accepted: 31 January 2017

\author{
*Correspondence: \\ Dr. Uday B. Rana, \\ E-mail: ubr.uday@gmail.com
}

Copyright: (c) the author(s), publisher and licensee Medip Academy. This is an open-access article distributed under the terms of the Creative Commons Attribution Non-Commercial License, which permits unrestricted non-commercial use, distribution, and reproduction in any medium, provided the original work is properly cited.

\begin{abstract}
Background: Hypertensive disorders of pregnancy (HDP) are among the main public health issues worldwide. They account for an estimated 10-15\% of maternal deaths globally. Among the hypertensive disorders of pregnancy, preeclampsia is most dangerous, occurring in $10 \%$ of first pregnancies, and in $20-25 \%$ of women with past history of hypertension. The objective of present study is to investigate the association of Doppler derived Indices of uterine artery resistance with composite of PIH/PET.

Methods: A prospective follow up observational study, including pregnant women at 11-13+6 weeks of gestation in whom Uterine Artery Resistance measured using Doppler ultrasound.

Results: A total of 100 subjects were enrolled, out of which 11 developed pre-eclampsia/ gestational hypertension. All Doppler indices (Resistance Index, Pulsatility Index and Systolic/Diastolic Index) had high specificities and negative predictive values.

Conclusions: The potential advantages of early screening of hypertensive disorders and their associated complications may allow investigations or prophylactic interventions before 20 weeks of gestation.
\end{abstract}

Keywords: First trimester Doppler, Pre-eclampsia, Uterine artery resistance

\section{INTRODUCTION}

Hypertensive disorders of pregnancy (HDP) are among the main public health issues worldwide. They account for an estimated $10-15 \%$ of maternal deaths globally. ${ }^{1}$ Among the hypertensive disorders of pregnancy, preeclampsia is most dangerous, occurring in $10 \%$ of first pregnancies, and in $20-25 \%$ of women with past history of hypertension. Pre-eclampsia is a pregnancy specific syndrome and it affects $2-5 \%$ of pregnancies in developed countries and is a major cause of maternal and perinatal mortality and morbidity. ${ }^{2}$ The likelihood of developing pre-eclampsia is increased by a number of factors in the maternal history like primigravidae, history of preeclampsia in previous pregnancies, history of preeclampsia in mother or sister, pre-existing diabetes mellitus, multiple gestations, history of chronic hypertension or chronic renal disease, presence of antiphospholipid antibody syndrome. ${ }^{3}$ However, screening by maternal history alone would identify only $30 \%$ and $20 \%$ of cases of early and late PE, respectively. ${ }^{1}$

The precise aetiology of pre-eclampsia is still unknown. The development of pre-eclampsia is thought to be a consequence of impaired trophoblastic invasion of the maternal spiral arteries and their conversion from narrow muscular vessels into wide non-muscular channels. In pre-eclampsia and IUGR there is inadequate trophoblastic invasion of spiral arteries which leads to impedance of blood flow in uterine arteries. ${ }^{4,5}$ The systemic endothelial 
dysfunction, leading to thrombotic phenomenon in the microcirculation, reduces the perfusion of tissues and organs, including the placenta itself, creating an even more hypoxemic environment. Chronic placental hypoxia causes both oxidative stress with consequent placental apoptosis and necrosis and also an increased expression of proinflammatory, antiangiogenic, and angiogenic factors, amplifying the systemic endothelial impairment. ${ }^{6}$

Several tests have been purported to predict preeclampsia but the underlying evidence often lacks quality and/or precision. The principle of identifying a reduced diastolic flow in the main uterine artery as a marker of this impaired placentation process by uterine artery Doppler during first trimester can be an effective method of predicting subsequent development of pre-eclampsia. It is a reliable, non-invasive, safe, rapid and easily reproducible tool.

Using Doppler, the pulsatility index is measured at 12 to 13 weeks of gestation, and when the pulsatility index comes in the upper quartile the risk of preeclampsia is increased by a factor of four. More recent studies have demonstrated the feasibility of uterine artery Doppler in the first trimester $\left(11-13^{+6}\right.$ weeks).

\section{METHODS}

A prospective follow up observational study was conducted in the Department of Obstetrics and Gynaecology in Kamla Nehru State hospital and in the Department of Cardiology at Indira Gandhi Medical College, Shimla was conducted w.e.f $1^{\text {st }}$ June 2013 to $31^{\text {st }}$ May 2014.

\section{Inclusion criteria}

Subjects attending routine antenatal clinic in between 11$13^{+6}$ weeks of gestation consenting to participate in the study were enrolled.

\section{Exclusion criteria}

- Presence of structural or chromosomal anomaly in the fetus

- Loss to follow up

- Those who got aborted

- Patients in whom uterine arteries were not visualised

- Patients with chronic hypertension

- Patients with cardio-pulmonary diseases

All eligible subjects who were willing to participate after informed consent were subjected to focussed history as per structured data recording format to record maternal and medical history followed by physical examination. The standard recommended guidelines were followed to record BP using Mercury sphygmomanometer with appropriate size cuff. Three readings were recorded at an interval of 2-3 minutes and average value was used for
BP record. Gestational age was calculated from LMP and confirmed by ultrasound in first trimester. Perinatal outcome was recorded by recording birth weight, preterm/full term, APGAR score, live birth/stillbirth.

\section{Measurement of uterine artery resistance}

The uterine artery resistance measurement was made by using phased array adult probe ofI E 133 Echo Machine of Phillips medical system through trans abdominal window. 2D tomographic images of uterus and cervical canal in sagittal plane were profiled and uterus and cervical canal at inner cervical os were imaged and then the plane of ultrasound beam was sweeped laterally on left and right to image uterine artery guided by colour flow Doppler imaging. Flow velocity waveforms were obtained from each uterine artery at the crossing with external iliac artery before division of uterine artery into branches. Once uterine artery was localized spectral pulse wave Doppler signals were recorded from both uterine arteries with an attempt to keep the angle of insonation between 30 - 60 degrees for reliable measurements of Doppler waveform derived indices. Three consecutive Doppler spectral wave forms were used on both sides to calculate Doppler derived indices of uterine artery resistance. The following indices of uterine artery resistance were used as predictors of PIH/PET:

S/D ratio (peak systolic/ late diastolic velocity ratio)

Resistance index (RI) (peak systolic velocity-end diastolic velocity/ peak systolic velocity)

Pulsatility index (PI) (peak systolic velocity-end diastolic velocity/ mean velocity)

Criteria for abnormal uterine artery Doppler derived indices were;

Increased Uterine artery PI; $>95^{\text {th }}$ percentile

Increased Resistance Index; $>95^{\text {th }}$ percentile

Increased $S / D$ ratio; $>95^{\text {th }}$ percentile

\section{Statistical analysis}

Statistical analysis was done using statistical software Epi info version 7 . $\mathrm{P}$ value $<0.05$ was considered as significant.

\section{RESULTS}

There were total of 100 subjects during this study period in whom Doppler study for uterine artery indices was done. Out of these, 11 developed pre-eclampsia or gestational hypertension (Group II). Remaining 89 were taken as control group (Group I). The demographic characteristics of the women under study were: the mean age of subjects in Group I and Group II were 
$25.11 \pm 2.62 \mathrm{SD}$ and $29.3 \pm 1.62 \mathrm{SD}$ respectively. Older age of women is related to development of hypertension. $84 \%$ of study population were from rural background. Maximum number of subjects in our study belonged to modified Kuppuswamy Class III i.e., middle lower. $45.5 \%$ of subjects who developed hypertension were nulliparous. The mean body mass index in Group I and Group II was $21.94 \pm 2.22 \mathrm{SD}\left(\mathrm{kg} / \mathrm{m}^{2}\right)$ and $24.53 \pm 2.43 \mathrm{SD}$ $\left(\mathrm{kg} / \mathrm{m}^{2}\right)$ respectively. Higher BMI is associated with preeclampsia ( $\mathrm{p}$ value of 0.000 ).

\section{Table 1 (A): Baseline characteristics of study population.}

\begin{tabular}{|c|c|c|c|}
\hline & Group I & Group II & P Value \\
\hline $\begin{array}{l}\text { Mean age } \\
\text { (years) }\end{array}$ & $25.11 \pm 2.62$ & $29.3 \pm 1.62$ & $0.000^{*}$ \\
\hline Parity & $1.76 \pm 0.754$ & $1.64 \pm 0.674$ & 0.707 \\
\hline $\begin{array}{l}\text { Previous } \\
\text { history of PIH } \\
(\%)\end{array}$ & 3.4 & 27.3 & $0.016^{*}$ \\
\hline $\begin{array}{l}\text { Family history } \\
\text { of PIH }(\%)\end{array}$ & 13.5 & 18.2 & 0.65 \\
\hline $\begin{array}{l}\text { Mean BMI } \\
\left(\mathrm{kg} / \mathrm{m}^{2}\right)\end{array}$ & $21.94 \pm 2.22$ & $24.53 \pm 2.43$ & $0.000^{*}$ \\
\hline $\begin{array}{l}\text { Mean systolic } \\
\text { BP (mmhg) }\end{array}$ & $107.6 \pm 5.96$ & $122 \pm 6.93$ & $0.000^{*}$ \\
\hline $\begin{array}{l}\text { Mean diastolic } \\
\mathrm{BP}(\mathrm{mmhg})\end{array}$ & $67.5 \pm 4.05$ & $78.91 \pm 5.75$ & $0.000^{*}$ \\
\hline $\begin{array}{l}\text { GA at the time } \\
\text { of scan (weeks) }\end{array}$ & $12.34 \pm 0.65$ & $12.22 \pm 0.58$ & \\
\hline
\end{tabular}

*Statistically significant.

In Group I, 3.4\% subjects had history of hypertension in previous pregnancy whereas in Group II, $27.3 \%$ had such history ( $p$ value $=0.016$ ). This is related to familial diathesis, personal predisposition with underlying thrombophilias and pre-existing vascular diseases which results in endothelial damage. $13.5 \%$ of subjects in Group I had history of pre-eclampsia in family and in Group II, $18.2 \%$ of subjects had such family history. Family history of diabetes mellitus was present in $16.9 \%$ subjects in Group I and $18.2 \%$ cases in Group II.

The mean systolic blood pressure $(\mathrm{mmHg})$ in the first trimester in the Group I was 107.6 \pm 5.96 SD as compared to Group II where the mean systolic blood pressure was $122 \pm 6.93 \mathrm{SD}$ ( $\mathrm{p}$ value<0.05). Diastolic blood pressure $(\mathrm{mmHg})$ in Group I had a mean value of $67.5 \pm 4.05$ SD where as in Group II, mean value came out to be $78.91 \pm 5.75 \mathrm{SD}$ and their difference was found to be statistically significant ( $\mathrm{p}$ value $<0.05$ ).

The mean value of mean arterial pressure (MAP) in Group I was $80.88 \pm 4.14$ SD and in Group II was 93.28 $\pm 5.12 \mathrm{SD}(\mathrm{mmHg})$.

The systolic/diastolic ratio (S/D ratio) >3.6 was taken as reference value. Sensitivity and specificity of systolic/diastolic ratio for predicting pre-eclampsia or gestational hypertension came out to be $18.2 \%$ and $92.1 \%$ respectively. Positive and negative predictive value of systolic/diastolic ratio was $22.2 \%$ and $90.1 \%$ respectively. With the normal Doppler values of S/D ratio in first trimester, we can exclude the women who will not develop hypertension later on in pregnancy. And those women with abnormal values could be closely followed up in the pregnancy and interventions could be taken accordingly. Resistance index (RI) of $>0.78$ was considered as reference value in the present study. The mean value of RI in Group I and Group II was $0.47 \pm 0.19$ $\mathrm{SD}$ and $0.55 \pm 0.21 \mathrm{SD}$ respectively.

Table 1 (B): Baseline characteristics of study population.

\begin{tabular}{|c|c|c|c|}
\hline & Group I & Group II & $\begin{array}{l}P \\
\text { value }\end{array}$ \\
\hline $\begin{array}{l}\text { Mean } \\
\text { systolic/diastolic } \\
\text { ratio }\end{array}$ & $2.38 \pm 0.69$ & $2.28 \pm 0.91$ & 0.25 \\
\hline $\begin{array}{l}\text { Mean resistance } \\
\text { index }\end{array}$ & $0.47 \pm 0.19$ & $0.55 \pm 0.21$ & $0.027^{*}$ \\
\hline $\begin{array}{l}\text { Mean pulsatility } \\
\text { index }\end{array}$ & $1.90 \pm 0.28$ & $1.98 \pm 0.26$ & 0.213 \\
\hline $\begin{array}{l}\text { GA at delivery } \\
\text { (weeks) }\end{array}$ & $38.97 \pm 0.68$ & $36.06 \pm 2.49$ & $0.003^{*}$ \\
\hline $\begin{array}{l}\text { Induction of } \\
\text { labour }(\%)\end{array}$ & 6.7 & 54.5 & $0.000^{*}$ \\
\hline $\begin{array}{l}\text { Delivery by } \\
\text { caesarean }(\%)\end{array}$ & 9 & 27.3 & 0.100 \\
\hline $\begin{array}{l}\text { Birth weight } \\
(\mathrm{kg})\end{array}$ & $2.93 \pm 0.15$ & $2.41 \pm 0.38$ & $0.001^{*}$ \\
\hline Stillbirth (\%) & 0 & 9.1 & $0.004^{*}$ \\
\hline $\begin{array}{l}\text { Apgar }<7 \text { at } 5 \\
\text { minute }(\%)\end{array}$ & 0 & 27.30 & $0.000^{*}$ \\
\hline
\end{tabular}

* Statistically significant.

The presence of resistance index (RI) more than $95^{\text {th }}$ percentile is associated with a significantly increased risk of development of pre-eclampsia ( $p$ value< 0.05 ). The specificity of resistance index (RI) came out to be $95.5 \%$ with a negative predictive value of $91.4 \%$ whereas sensitivity was $27.3 \%$ with positive predictive value of 42.9\%. A value of more than 2.35 was taken as reference value of pulsatility index (PI). Mean PI in Group I and Group II was $1.90 \pm 0.28 \mathrm{SD}$ and $1.98 \pm 0.26 \mathrm{SD}$ respectively. The sensitivity and specificity of PI in predicting pre-eclampsia was $18.2 \%$ and $93.3 \%$ respectively, whereas positive and negative predictive value was $25 \%$ and $90.2 \%$ respectively.

In the present study, the mean gestational age at the time of delivery in Group I was 38.97 \pm 0.68 SD weeks as compared to Group II where gestational age at the time of delivery came out to be $36.06 \pm 2.49 \mathrm{SD}$ weeks ( $\mathrm{p}$ value $=$ 0.003 ). Labour was induced in $6.7 \%$ cases in Group I whereas in Group II, $54.5 \%$ cases were induced ( $p$ value $=0.000$ ). Labour was induced early due to high blood 
pressure at earlier gestation to prevent the dreaded complications of pre-eclampsia in mother and fetus. $91 \%$ cases in Group I had vaginal delivery and $9 \%$ delivered by lower segment caesarean section as compared to Group II where $72.7 \%$ subjects had normal vaginal delivery whereas $27.3 \%$ were terminated by lower segment caesarean section.

Table 2: Feasibility of Doppler indices.

\begin{tabular}{|l|l|l|l|}
\hline \multicolumn{2}{|c|}{ Group I } & Group II & P Value \\
\hline $\begin{array}{l}\text { Mears age } \\
\text { (earity }\end{array}$ & $25.11 \pm 2.62$ & $29.3 \pm 1.62$ & $0.000^{*}$ \\
\hline Parity & $1.76 \pm 0.754$ & $1.64 \pm 0.674$ & 0.707 \\
\hline $\begin{array}{l}\text { Previous history } \\
\text { of PIH (\%) }\end{array}$ & 3.4 & 27.3 & $0.016^{*}$ \\
\hline $\begin{array}{l}\text { Family history } \\
\text { of PIH (\%) }\end{array}$ & 13.5 & 18.2 & 0.65 \\
\hline $\begin{array}{l}\text { Mean BMI } \\
\text { (kg/m²) }\end{array}$ & $21.94 \pm 2.22$ & $24.53 \pm 2.43$ & $0.000^{*}$ \\
\hline $\begin{array}{l}\text { Mean systolic } \\
\text { BP (mmhg) }\end{array}$ & $107.6 \pm 5.96$ & $122 \pm 6.93$ & $0.000^{*}$ \\
\hline $\begin{array}{l}\text { Mean diastolic } \\
\text { BP (mmh) }\end{array}$ & $67.5 \pm 4.05$ & $78.91 \pm 5.75$ & $0.000^{*}$ \\
\hline $\begin{array}{l}\text { GA at the time } \\
\text { of scan (weeks) }\end{array}$ & $12.34 \pm 0.65$ & $12.22 \pm 0.58$ & \\
\hline
\end{tabular}

The mean birth weight $(\mathrm{kg})$ at the time of delivery in Group I was $2.93 \pm 0.15$ SD whereas in Group II, who developed hypertension, the mean birth weight was $2.41 \pm 0.38 \mathrm{SD}(\mathrm{p}<0.05)$. This can be explained by the fact that in such subjects (Group II) early inductions were required which lead to preterm deliveries and the hypertensive disorders lead to intrauterine growth restriction (IUGR) because of uteroplacental insufficiency. There was no stillbirth in Group I as compared to Group II where one subject had a still birth ( $\mathrm{p}$ value $=0.004) .27 .3 \%$ of neonates of subjects who developed hypertension had apgar score less than 7 at five minute of birth. This was statistically significant ( $p$ value $<0.05)$.

\section{DISCUSSION}

Identification of women at high risk for pre-eclampsia during the first trimester could potentially improve pregnancy outcome because intensive maternal and fetal monitoring in such patients would lead to an earlier diagnosis of the clinical signs of the disease and the associated fetal growth restriction and can avoid the development of serious complications. Early identification of these high-risk women would help to determine whether the administration of prophylactic therapy would prevent or significantly ameliorate these conditions. Our study was conducted to identify a suitable screening program for hypertensive diseases of pregnancy during the first trimester with the potential to improve pregnancy outcomes and avoid serious complications. This study suggested that the risk of developing hypertensive disorders was more in primigravidae as was seen in studies carried out by Plasencia et al and Herraiz et al. ${ }^{7,8}$

Increased body mass index was an important risk factor for the development of hypertensive disorders inspite of the ethnic differences. $7.9 \%$ of subjects in group I and $18.2 \%$ in group II had significant values of S/D ratio which can further predict the early development of hypertensive disorders in early first trimester. Uterine artery indices especially resistance index (RI) reflects the degree of trophoblastic invasion in the first trimester. RI appears to be the most repeatable and reproducible measurement at 11 to 14 weeks of gestation. The presence of RI more than $95^{\text {th }}$ percentile is associated with a significantly increased risk of development of preeclampsia. Increased RI increases a woman's odd of developing early onset preeclampsia compared with women who had late onset or no preeclampsia as was seen in our study, i.e., the mean value of RI in group I and group II are $0.47 \pm 0.19$ and $0.55 \pm 0.21$ ( $\mathrm{p}$ value $<0.05)$.

Uterine artery pulsatility index (PI) is useful in the first trimester mainly in the cases that are characterized by a high grade of placental ischemia. It is not that useful in less severe forms. Our study demonstrated lower impedance in the uterine artery of normal outcome pregnancies than in the hypertensive cases suggesting that the lack of a normal uteroplacental circulation at this early stage of pregnancy may partly predict the development of hypertension later on. Out of total 100 subjects, there was only one case of stillbirth, which was in-group II, and rest all were live births. The difference was statistically significant ( $\mathrm{p}$ value $<0.05$ ).

\section{CONCLUSION}

We suggest that there is a definite clinical role for uterine Doppler velocimetry in early pregnancy to identify pregnancies with an increased risk of developing hypertensive disorders in an unselected Indian population. Early uterine Doppler might be particularly useful to identify the most severe spectrum of the disease, although this may not be so in cases with a lower grade of placental ischemia. The potential advantages of early screening of hypertensive disorders and their associated complications may allow investigations or prophylactic interventions before 20 weeks of gestation. Nonetheless, it is necessary to identify the at-risk population at such early stages of pregnancies. Future researches combining uterine Doppler parameters with other screening tests are required. For this purpose, a multivariate analysis combining the uterine artery indices with the classical clinical risk factors are required.

\section{Funding: No funding sources}

Conflict of interest: None declared

Ethical approval: The study was approved by the Institutional Ethics Committee 


\section{REFERENCES}

1. Abdelaziz A, Maher MA, Sayyed TM, Bazeed MF, Mohamed NS. Early pregnancy screening for hypertensive disorders in women without a-priori high risk. Ultrasound Obstet Gynecol. 2012;40:398405.

2. Napolitano R, Melchiorre K, Arcangeli T, Dias T, Bhide A, Thilaganathan B. Screening for preeclampsia by using changes in uterine artery Doppler indices with advancing gestation. Prenat Diagno. 2012;32:180-4.

3. Poon LCY, Staboulidou I, Maiz N, Plasencia W, Nicolaides KH. Hypertensive disorders in pregnancy: screening by uterine artery Doppler at 11-13 weeks. Ultrasound Obstet Gynecol. 2009;34:142-8.

4. Gupta S, Gupta PK, Bodani P, Khamesra A. Transvaginal Doppler of uteroplacental circulation in earlyprediction of pre-eclampsia by observing bilateral uterine artery notch and resistance index at 12-16 weeks of gestation. J Obstet Gynecol India. 2009;59:541-6.

5. Yu CK, Smith GCS, Papageorghiou AT, Cacho AM, Nicolaides KH. An integrated model for the prediction of pre-eclampsia using maternal factors and uterine artery Doppler velocimetry in unselected low-risk women. Am J Obstet Gynecol. 2005;193:429-36.

6. Genovese F, Stracquadanio M, Ingala A, Ciotta L, Agati AD, Pafumi C, et al. Screening for preeclampsia by uterine artery doppler velocimetry in the late first trimester of pregnancy. Med. Res. Chron. 2014;1:60-72.

7. Herraiz I, Escribano D, Gomez-Arriaga PI, Hernandez-Garcia JM, Herraiz MA, Galindo A. Predictive value of sequential models of uterine artery Doppler in pregnancies at high risk for preeclampsia. Ultrasound Obstet Gynecol. 2012;40:68-74.

8. Plasencia W, Maiz N, Bonino S, Kaihura C and Nicolaides KH. Uterine artery Doppler at $11+0$ to $13+6$ weeks in the prediction of preeclampsia. Ultrasound Obstet Gynecol. 2007;30:742-9.

Cite this article as: Rana UB, Minhas $S$, Negi $P$, Pathania K, Kaur SP. To study the association of Doppler derived Indices of uterine artery resistance with composite of PIH/PET. Int J Reprod Contracept Obstet Gynecol 2017;6:919-23. 